\title{
KOMPOR BIOMASSA SISTEM BATCH MENGGUNAKAN BAHAN BAKAR SEKAM PADI
}

\author{
Mustaqim Kamba. ${ }^{1}$, Romi Djafar. ST.,MT. ${ }^{2)}$ \\ ${ }^{1)}$ Mahasiswa Politeknik Gorontalo, Kampus Puncak Desa Panggulo Bone Bolango \\ ${ }^{2)}$ Tim Pengajar pada Program Studi Mesin dan Peralatan Pertanian, Politeknik Gorontalo
}

\begin{abstract}
ABSTRAK
Biomassa merupakan material biologis berupa tumbuhan dan hewan yang dapat diubah menjadi sumber energi. Berbagai jenis biomassa dari hasil sisa pengolahan bahan pertanian seperti sekam padi, tongkol jagung dan serbuk kayu yang selama ini belum dimanfaatkan secara maksimal. Biomassa ini dapat digunakan sebagai bahan bakar alternatif pengganti minyak bumi yang cocok dikembangkan di Indonesia khususnya propinsi Gorontalo yang memiliki tanaman padi yang sekali panen menghasilkan limbah pertanian yang sangat melimpah yaitu sekam padi. Kebiasaan yang sering dilakukan oleh petani adalah dengan melakukan pembakaran sekam padi yang membawa dampak pada pencemaran lingkungan, yang bersumber dari asap pembakaran sekam padi tersebut. Maka di buatlah fabrikasi kompor gasifikasi biomassa sistem batch dengan menambahkan kepala kompor dan menggunakan blower sebagai udara primer. Oleh karena itu, Teknologi kompor gasifikasi yang dapat mengkonversi biomassa menjadi energi panas yang hemat energi dan ramah lingkungan sebagai solusi yang tepat untuk diperkenalkan kepada pemerintah daerah maupun masyarakat. Tujuan dari pembuatan kompor ini adalah merancang fabrikasi kompor biomassa dengan bahan baku sekam padi. Hasil fabrikasi telah diuji kinerjanya dengan jumlah ukuran bahan bakar yaitu $1 \mathrm{~kg}$. Metode yang digunakan adalah water boiling test (WBT) terhadap 2 liter air. Berdasarkan pengujian didapatkan hasil waktu mendidig tercepat terjadi pada menit ke 5,36. komsumsi bahan bakar yang dihasilkan berturut-turut $1,1 \mathrm{~kg} / \mathrm{h}$; $1.9 \mathrm{~kg} / \mathrm{h}$ dan $2.5 \mathrm{~kg} / \mathrm{h}$. Power output yang didapatkan adalah terendah sebesar $0.8 \mathrm{kWh}$ dan tertinggi sebesar $1.8 \mathrm{kWh}$. Sedangkan efesiensi termal kompor gasifikasi dihasilkan sebesar $23.8 \%$.
\end{abstract}

Kata Kunci: Biomassa, Kompor, Hemat energi, Efisiensi termal.

\section{STORAGE OF BATCH BIOMASS SYSTEM USING MATERIALS BAKAR SEKAM PADI}

\begin{abstract}
Biomass is a biological material in the form of plants and animals that can be converted into energy sources. Various types of biomass from the residual processing of agricultural materials such as rice husks, corn cobs and wood powder that have not been utilized optimally. This biomass can be used as an alternative fuel to replace petroleum which is suitable to be developed in Indonesia, especially Gorontalo province which has rice plants which once harvest produce very abundant agricultural waste, namely rice husk. The habit that is often done by farmers is by burning rice husks that have an impact on environmental pollution, which is sourced from the smoke from burning rice husks. So fabricating a batch system of biomass gasification stoves was made by adding stove heads and using blowers as primary air. Therefore, the technology of gasification stoves that can convert biomass into heat energy that is energy efficient and environmentally friendly is the right solution to be introduced to local governments and the community. The purpose of making this stove is to design the fabrication of biomass stoves with raw materials of rice husk. The results of fabrication have been tested for performance with the amount of fuel size which is $1 \mathrm{~kg}$. The method used is a water boiling test (WBT) to 2 liters of water. Based on the test results obtained the fastest boiling time occurred in the 5.36 minutes. the consumption of fuel produced is $1.1 \mathrm{~kg} / \mathrm{h}$ respectively; $1.9 \mathrm{~kg} / \mathrm{h}$ and $2.5 \mathrm{~kg} / \mathrm{h}$. The power output obtained is the lowest at $0.8 \mathrm{kWh}$ and the highest at $1.8 \mathrm{kWh}$. While the thermal efficiency of the gasification cooker is $23.8 \%$
\end{abstract}


Keyword :. Biomass, Stove, Energy saving, Thermal efficiency.

\section{PENDAHULUAN}

\section{Latar Belakang}

Kebutuhan dan konsumsi energi semakin meningkat sejalan dengan bertambahnya populasi manusia dan meningkatnya perekonomian masyarakat. Di Indonesia kebutuhan dan konsumsi energi terfokus kepada penggunaan bahan bakar minyak bumi yang cadangannya kian menipis. Oleh karena itu, mengatasi masalah harga minyak dan gas yang semakin mahal, serta cadangannya yang terbatas maka diperlukan usaha yang terprogram dan terarah untuk mencari energi alternatif. Diantara sumber-sumber energi alternatif tersebut, energi biomassa merupakan sumber energi yang perlu mendapat prioritas dalam pengembangannya. (Basu, 2013).

Biomassa merupakan material biologis berupa tumbuhan dan hewan yang dapat diubah menjadi sumber energi. Berbagai jenis biomassa dari hasil sisa pengolahan bahan pertanian seperti sekam padi, tongkol jagung, ampas tebu, serbuk kayu, yang selama ini belum dimanfaatkan secara maksimal. Biomassa ini dapat digunakan sebagai bahan bakar alternatif pengganti minyak bumi yang cocok dikembangkan di Indonesia karena jumlahnya yang melimpah. (Babu dan Chaurasia, 2003).

Di Indonesia khususnya di Provinsi Gorontalo memiliki tanaman padi yang sekali panen menghasilkan limbah pertanian yang sangat melimpah. Salah satu limbah pertanian tersebut adalah sekam padi. Kebiasaan yang sering dilakukan oleh petani adalah dengan melakukan pembakaran sekam padi. Hal inilah yang membawa dampak pada pencemaran lingkungan, yang bersumber dari asap pembakaran sekam padi tersebut.

Salah satu upaya yang dapat dilakukan adalah penggunaan kompor biomassa sebagai solusi yang tepat terutama membantu masyarakat dalam keperluan memasak disamping ketersediaan bahan baku yang melimpah dan murah, kompor biomassa dapat memberikan solusi untuk mengurangi dampak polusi lingkungan akibat asap yang dilakukan sebagai dampak pembakaran langsung.

Berbagai penelitian dan pengembangan yang telah dilakukan untuk mendesain dan evaluasi kinerja kompor gasifikasi biomassa yaitu mengatur parameter untuk mendapatkan performa kompor yang lebih baik. Pengaruh pemilihan parameter terhadap performa dan isi dari pembakaran biomassa pada kompor gasifikasi (Bhattacharya, 2002). Penelitian yang telah dilakukan dengan memilih berbagai parameter berupa kandungan kadar air, ukuran bahan bakar, ruang pembakaran serta ukuran kipas udara primer yang digunakan. Tujuan penelitian menentukan jenis kompor yang memiliki efisiensi yang lebih tinggi berdasarkan jenis ukuran bahan bakar. Pengujian penelitian menggunakan water boiling time (WBT).

Kompor pengembangan gasifikasi kompor dengan blower tunggal yang memiliki kadar emisi rendah, kemapuan stabil, yang dapat dikontrol menggunakan bahan bakar dalam bentuk pellet dengan basis suplai udara menggunakan kipas angin sebagai udara primer pembakaran beserta secondary air untuk pembakaran stoikio metri. Metode pengembangan eksperimen dilakukan menggunakan berbagai tipe bahan bakar, ukuran ruang bakar dan desain ruang suplai udara pembakaran. Hasil penelitian menunjukkan bahwa desain yang memiliki efisiensi tinggi serta kadar emisi rendah sangat dipengaruhi oleh perbandingan udara dan bahan bakar yang benar. (Mukunda, 2010).

Berdasarkan uraian masalah pada kompor sebelumnya maka penulis mendesain alat kompor biomassa sistem batch dengan optimal warna api agak kebiru-biruan yang di sebabkan masuknya udara primer berasal dari kipas angin, udara secondary sebagai udara pembakaran menggunakan bahan bakar limbah sekam padi. Pemilihan forced draft karena lebih unggul dibanding natural draft untuk ukuran kompor skala kecil sekaligus memiliki tingkat efisiensi yang lebih baik.

\section{Rumusan Masalah}

Berdasarkan latar belakang dan penelitian terdahulu maka rumusan masalah pada penulisan tugas akhir ini adalah:

1. Bagaimana mendesain kompor biomassa dengan menggunakan sistem Batch?

2. Bagaimana model burner kompor yang menghasilkan nyala api kebiru-biruan?

3. Bagaimana pengaturan efesiensi termal kompor biomassa sistem batch?

\section{Tujuan Penilitian}

Berdasarkan latar belakang dan perumusan masalah sebelumnya maka dari tujuan penulisan tugas akhir ini adalah:

1. Dapat mendesain alat kompor biomassa sistem Batch menggunakan bahan bakar sekam padi.

2. Dapat membuat burner/kepala kompor biomassa.

3. Untuk mengetahui pengaruh variasi kecepatan udara terhadap efisiensi termal kompor.

\section{Batasan Masalah}

Berdasarkan tujuan penelitian maka dari batasan masalah tugas akhir ini adalah:

1. Bahan bakar yang digunakan hanyalah limbah sekam padi.

2. Pengujian terfokus pada parameter input secara baik. 
3. Serta mengetahui waktu efisiensi termal yang akurat.

\section{Manfaat Penilitian}

Adapun manfaat dari penulisan tuga akhir ini adalah:

1. Pemanfaatan dan peningkatan energi biomassa sebagai subtitusi kebutuhan energi untuk memasak bagi rumah tangga.

2. Mampu mengembangkan pemanfaatan limbah sekam padi menjadi energi alternatif yang berguna bagi masyarakat dan memberikan kontribusi dalam rangka penghematan bahan bakar fosil.

3. Mengurangi dampak polusi dari limbah sekam padi akibat pembakaran langsung.

\section{TINJAUAN PUSTAKA}

\section{Biomassa}

Biomassa merupakan bahan biologis yang berasal dari organisme atau makhluk hidup. Dalam berbagai situasi, biomassa juga didefinisikan sebagai bahan-bahan organik berumur relatif muda yang berasal dari tumbuhan atau hewan, baik yang terbentuk dari hasil produksinya, sisa metabolismnya, ataupun limbah yang di hasilkan. Biomassa dapat di peroleh dari berbagai bidang industri budidaya, baik pertanian, perkebunan, kehutanan, peternakan, maupun perikanan. Biomassa umumnya mempunyai kadar volatile relatif tinggi, dengan kadar karbon tetap yang rendah dan kadar abu lebih rendah disbandi ngkan batu bara. Biomassa juga memiliki kadar volatile yang tinggi (sekitar $60-80 \%$ ) disbanding kadar volatile batubara, sehingga biomass lebih reaktif dibandingkan batubara. Biomasa bersifat mudah didapatkan, ramah lingkungan dan terbarukan. Sifat biomassa yang merupakan energi dengan katagori sumber energi terbarukan mendorong penggunaanya menuju skala yang lebih besar lagi sehingga manusia tidak hanya tergantung dengan energi fosil. (Anonimous, 2010).

Salah satu potensi biomassa indonesia adalah tanaman padi. Proses penggilingan padi menghasilkan 20-30\% limbah sekam padi. Dalam kehiupan seharihari sekam padi biasanya jarang sekali dimanfaatkan oleh masyarakat . Hal ini dikarenakan sekam padi dianggap limbah pertanian yang berupa residu dari hasil panen, jika presentase sekam padi yang tinggi tersebut dibiarkan tentunya kelak akan menjadi salah satu problem lingkungan. Khusus untuk derah Tengah sendiri pada tahun 2012 produksi padi mencapai $10,199,014.00$ juta ton, yang artinya menghasilkan limbah sekam padi sekitar 2,039,802.8 juta ton. (Bps, 2012).

\section{Sekam Padi}

Sekam adalah bagian dari bulir padi-padian (serealia) berupa lembaran yang kering, bersisik, dan tidak dapat dimakan, yang melindungi bagian dalam (endospermiumdan embrio). Sekam dapat dijumpai pada hampir semua anggota rumput-rumputan (Poaceae), meskipun pada beberapa jenis budidaya ditemukan pula variasi bulir tanpa sekam (misalnya jagung dan gandum). Sekam padi merupakan sumber daya alam yang dapat diperbaharui dimana keberadaannya sangat melimpah di Indonesia yang merupakan negara agraris. Pada setiap penggilingan padi akan terlihat tumpukan bahkan gunungan sekam yang semakin lama semakin tinggi. Sekam dikategorikan sebagai biomasa yang dapat digunakan untuk berbagai kebutuhan seperti bahan baku industri, pakan ternak dan energi atau bahan bakar. Energi biomasa berasal dari sekam merupakan salah satu energi alternatif terbarukan. Umumnya, produksi padi secara rata-rata menghasilkan $55 \%$ beras utuh, $5 \%$ beras patah, 20\% kulit sekam padi, dan $10 \%$ dedak halus dan bekatul. Artinya, potensi terbesar dari hasil panen padi adalah energi biomassa sekam padi. Bila produksi padi Indonesia tahun 2012 adalah sebesar 69,06 juta ton gabah kering giling (GKG), maka potensi sekam yang dapat dikonversi menjadi energi adalah sebesar 13,8 juta ton (BPS 2013). Sekam mengandung bahan kimia selulosa yang mampu menunjang pembakaran yang merata dan stabil. Menurut Dr Irzaman penemu tungku sekam, nilai energisekam padi memang lebih rendah dibanding briket batu bara muda yang mengandung energi 5.500 $\mathrm{kkal} / \mathrm{kg}$, minyak tanah $8.900 \mathrm{kkal} / \mathrm{liter}$, dan elpiji $11.900 \mathrm{kkal} / \mathrm{kg}$, sedangkan panas pembakaran sekam hanya $3.300 \mathrm{kkal} / \mathrm{kg}$. Meskipun begitu bila dibandingkan dengan minyak tanah dan gas untuk mendidihkan 6 liter air dengan menggunakan sekam padi diperlukan waktu 12-18 menit dengan biaya hanya Rp300, sedangkan dengan menggunakan gas diperlukan waktu 11 menit dengan biaya Rp500, dan dengan menggunakan minyak tanah selama 25 menit dengan biaya Rp350 (LPPM-IPB 2008).

Dibawah ini merupakan tabel analisis proksimate dan ultimate sekam padi yang ditujukan pada Tabel 2.1sebagai berikut:

Tabel 2.1 Analisis Proximate dan Ultimate sekam Sumber: Madhiyanon, (2010)

\begin{tabular}{lc}
\hline \multicolumn{1}{c}{ Parameter } & Nilai (\%)erat) \\
\hline Moisture & 10,3 \\
Volatile Matter & 55,6 \\
Fixed Carbon & 20,1 \\
Ash & 14 \\
Carbon & 38 \\
Hydrogen & 4,55 \\
Nitrogen & 0,69 \\
Oxygen & 32,4 \\
\hline
\end{tabular}

Menurut data badan pusat statistik (BPS) pada tahun 2013 jumlah produksi padi mengalami kenaikan sebesar 2,24 juta ton dibanding tahun 2012. Kenaikan produksi padi pada tahun 2013 yang relatif besar 
terjadi di Provinsi Jawa Barat, Sumatera Selatan, Banten, Aceh dan Kalimatan Barat dan 20- $22 \%$ dari jumlah tersebut merupakan sekam. Dari banyaknya sekam padi tersebut masih sedikit yang dimanfaatkan menjadi salah satu sumber energi alternatif. Sedikitnya pemanfaatan sekam padi untuk dikonversi menjadi energi, khususnya melalui gasifikasi disebabkan karena masih banyaknya kendala yang terjadi pada saat proses gasifikasi. Sekam padi yang selama ini dipandang sebagai limbah yang dianggap sebagai polutan lingkungan sebenarnya adalah salah satu sumber energi biomasa yang dipandang penting untuk menanggulangi krisis energi belakangan ini khususnya di daerah pedesaan. Ketersediaan sekam padi di hampir 75 negara di dunia diperkirakan sekitar 100 juta ton dengan energi potensial berkisar $1,2 \times 10^{9} \mathrm{GJ} /$ tahun dan mempunyai nilai kalor rata-rata $15 \mathrm{MJ} / \mathrm{kg}$.

\section{Kompor Berbahan Bakar Biomassa}

Kompor berbahan bakar biomassa sebenarnya telah ditemukan di sejumlah daerah dan di negara lain. Perbedaan kompor biomassa dengan kompor konvensional lain yaitu, jika kompor konvensional berbahar bakar minyak atau gas, kompor biomassa menggunakan bahan bakar seperti misalnya kayu, plastik, dan daun kering. Uniknya, ketika dibakar dalam kompor biomassa, bahan-bahan itu hampir tidak menimbulkan polusi sehingga ramah lingkungan. Penelitian yang telah dilakukan Nurhuda menunjukan satu kilogram bahan bakar bisa dinyalakan api selama satu jam. Untuk memperbesar nyala api, bisa digunakan kipas blower listrik. Api biru muncul karena pembakarannya dua tahap. Pertama, terjadi pembakaran kayu, oksigen, metana, dan nitrogen yang. Oksigen yang terbakar menghasilkan api membiru. Kedua pembakaran arang dan oksigen menghasilkan karbon dioksida. Pembakaran kedua ini menyala lebih baik dibandingkan dengan nyala pembakaran pertama. Pada Gambar 2.1 ditujukan struktur kompor biomassa UB-03 Nurhuda sebai berikut:

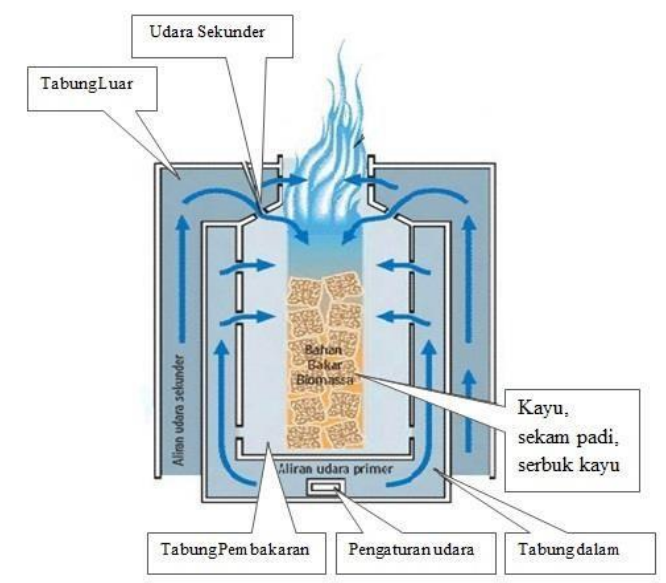

Gambar 2.1 Struktur Kompor Biomassa UB-03 Nurhuda
Secara kimia, asap pembakaran tersusun atas gas-gas diantaranya adalah $\mathrm{H}_{2}, \mathrm{CO}, \mathrm{CH}_{4}, \mathrm{CO}_{2} \mathrm{~B}, \mathrm{SOx}$, NOx dan uap air. Sebagian gas-gas tersebut, yaitu hydrogen $\left(\mathrm{H}_{2}\right)$, karbon monoksida $(\mathrm{CO})$, dan metana $\left(\mathrm{CH}_{4}\right)$ adalah gas-gas yang dapat terbakar, sehingga dapat dimanfaatkan menjadi bahan bakar. Untuk meningkatkan efisiensi penggunaan biomassa sebagai bahan bakar, maka asap yang dihasilkan pada proses pengarangan harus dibakar lagi untuk kedua kali dan menghasilkan api yang mempunyai nyala yang lebih bersih (Nurhuda, 2008).

Pengujian terhadap tungku berbahan bakar sekam padi pernah dilakukan oleh balai besar litbang pascapanen di karawang. Hasil pengamatan yang dilakukan di laboratorium karawang balai besar Litbang Pascapanen menunjukan bahwa penggunaan tungku sekam cukup prospektif untuk digunakan pada skala rumah tangga petani/pedesaan karena mudah mendapatkan bahan bakarnya, yaitu sekam padi. Hasil uji pemanasan dengan tungku sekam oleh balai besar

\begin{tabular}{|c|c|c|c|c|}
\hline Pemasak/tungku & $\begin{array}{c}\text { Berat } \\
\text { sekam } \\
\text { (gr) }\end{array}$ & $\begin{array}{l}\text { Volume } \\
\text { air }\end{array}$ & $\begin{array}{c}\text { Waktu } \\
\text { didi } \\
\text { h } \\
\text { (me } \\
\text { nit) } \\
\end{array}$ & $\begin{array}{c}\text { Suhu } \\
\text { maksimal } \\
\left({ }^{\circ} \mathrm{C}\right)\end{array}$ \\
\hline $\begin{array}{l}\text { Kompor } \\
\text { (sekam segar) }\end{array}$ & 600 & 6 & $12-15$ & 360 \\
\hline $\begin{array}{lr}\text { Briket } & \text { arang } \\
\text { sekam } & \text { (perekat } \\
\text { tapioka) } & \end{array}$ & 600 & 6 & 51 & 360 \\
\hline $\begin{array}{lr}\text { Briket } & \text { arang } \\
\text { sekam } & \text { (perekat } \\
\text { tanah) } & \end{array}$ & 1200 & 6 & 50 & 360 \\
\hline
\end{tabular}

litbang pascapanen ditujukan dalam Tabel 2.2 sebagai berikut:

Tabel 2.2 Uji Pemanasan Tungku Sekam Oleh Balai Besar Litbang.

Sumber: Balai Besar Litbang Pascapanen Karawang, 2006.

Laju kecepatan aliran udara primer (udara yang dihasilkan kipas) kompor Belonio diketahui ternyata mempengaruhi besarnya nyala api yang dihasilkan. Apabila putaran kipas semakin kencang, maka nyala api akan semakin besar. Angin yang terdapat di udara sekitar juga mempengaruhi nyala api, karena semakin kencang angin yang berhembus di sekitar akan membuat nyala api tidak stabil bahkan apabila angin yang berhembus terlalu kencang akan memadamkan api, maka hendaknya pengoperasian kompor Belonio dilakukan di dalam ruangan.

\section{Gasifikasi}

Gasifikasi adalah suatu teknologi proses yang mengubah bahan padat menjadi gas. Bahan padat yang dimaksud adalah bahan bakar padat yang termasuk diantaranya biomassa, batubara, dan arang. Gas yang dimasksud adalah gas-gas yang keluar dari proses gasifikasi dan umumnya berbentuk $\mathrm{CO}, \mathrm{CO}_{2}, \mathrm{H}_{2}, \mathrm{CH}_{4}$. Proses gasifikasi dari biomassa terjadi pada temperatur 
yang tinggi dengan penambahan oksigen yang terkontrol, produk berupa campuran gas $\mathrm{CO}$ dan $\mathrm{H}_{2}$ dikenal sebagai syngas dan bisa digunakan sebagai subtitusi gas alami. Reaksi dasar gasifikasi adalah:

$\mathrm{Cn}+0,55 \mathrm{n} \mathrm{O} \rightarrow \mathrm{nCO}+0,5 \mathrm{~m} / \mathrm{H}_{2}$

Proses gasifikasi pada hakikatnya menoksidasi suplai hidro karbon pada lingkungan yang terkontrol untuk memproduksi gas sintetis yang memiliki nilai komersial yang signifikan. Gasifikasi merupakan suatu alternatif yang menarik karena proses ini mencegah pembentukan dioksin dan senyawa aromatik, proses gasifikasi juga menghasilkan reduksi utama pada volume input biomassa rata-rata 75\%. Pada Gambar 2.2 ditujukan grafik yang menjelaskan tentang perbedaan antara gasifikasi, periolisis dan pembakaran.

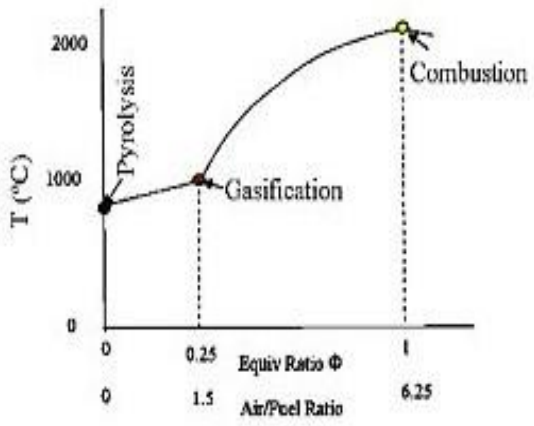

Gambar 2.2 Grafik perbedaan gasifikasi, periolisis dan pembakaran.

Dapat disimpulkan berdasarkan Gambar 2, perbedaan gasifikasi, periolisis, dan pembakaran berdasarkan kebutuhan udara yang diperlukan selama proses:

$>$ Jika jumlah udara: bahan bakar (AFR/air fuel ratio) $=0$, maka disebut periolisis.

$>$ Jika AFR<1,5 maka disebut gasifikasi.

$>$ Jika AFR>1,5 maka disebut pembakaran.

Berdasarkan medium gasifikasi, reactor gasifikasi (gasifier) dapat diklasifikasikan menjadi 2 kelompok ( Prabowo dan Nandana, 2010):

1. Aliran udara, dimana udara sebagai medium gasifikasinya .

2. Aliran oksigen, dimana oksigen murni sebagai medium gasifikasinya.

Gasifikasi adalah rincian termal lengkap biomassa menjadi gas yang mudah terbakar, mudah menguap, char, dan abu dalam reaktor tertutup atau gasifier. Gasifikasi adalah langkah-dua, endotermik proses. Pada pirolisis, reaksi pertama, komponen volatil dari bahan bakar yang menguap pada suhu di bawah $600^{\circ} \mathrm{C}$ oleh serangkaian reaksi yang kompleks. Termasuk dalam uap volatil adalah hidro karbon gas, hidrogen, karbon monoksida, karbon dioksida, tar, dan uap air.

Sebagai bahan bakar biomassa cenderung memiliki komponen yang lebih mudah menguap (70-86\% pada basis kering) dibandingkan batubara (30\%), pirolisis memainkan peran lebih besar dalam gasifikasi biomassa daripada di gasifikasi batubara.Char (fixed carbon) dan abu adalah pirolisis oleh-produk, yang tidak menguap. Pada langkah kedua, char gasifikasi melalui reaksi dengan oksigen, uap, karbon monoksida dan hidrogen.Panas yang dibutuhkan untuk reaksi endotermik gasifikasi dihasilkan oleh pembakaran bagian dari bahan bakar, char, atau gas, tergantung pada teknologi reaktor. Secara global gasifikasi diklasifikasian menjadi: up draft, downdraft, dan Crossdraft.

\section{$>\quad$ Updraft}

Tipe yang paling sederhana dari gasifikasi adalah Up draft. Biomassa dimasukkan dari bagian atas reaktor dan bergerak kebawah menghasilkan gas dan arang, tempat udara masuk berada dibawah dan gas yang dihasilkan keluar kea rah atas. Pada tipe up draft bahan bakar bergerak berlawanan arah dengan zona aliran gas melewatizona pengeringan, zona distilasi, zona reduksi, dan zona pembakaran. Pada gambar 2.3 ditujukan proses gasifikasi dengan tipe up draft.
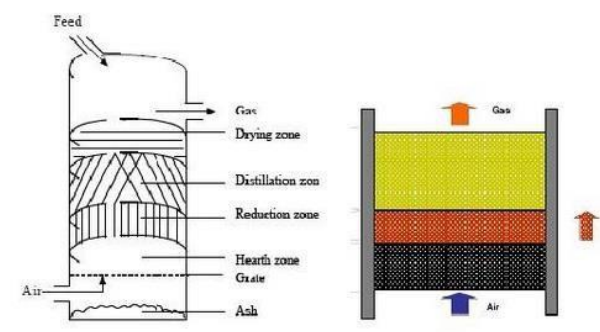

Gambar 2.3 Gasifikasi tipe up draft

\section{$>\quad$ Down draft}

Pada tipe down draft biomassa dimasukkan melalui atas begitu pula dengan udara yang masuk. Gas yang dihasilkan akan mengalir kebawah reaktor, aliran biomassa dan udara searah. Kelebihan dari tipe down draft adalah menghasilkan gas dengan kandungan tar rendah. Pada Gambar 2,4ditujukan proses gasifikasi dengan tipe down draft.
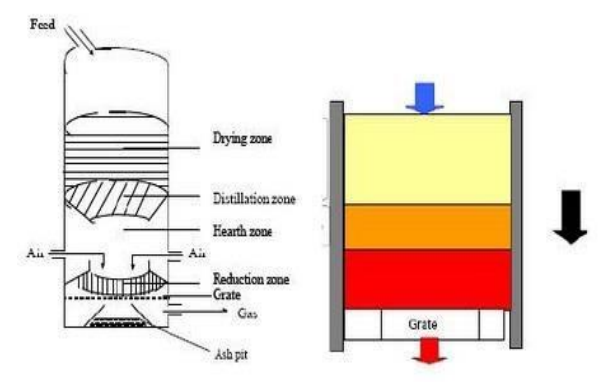

Gambar 2.4 Gasifikasi tipe down draft

\section{$>\quad$ Cross draft}

Pada tipe cross draft biomassa dimasukkan melalui atas, udara masuk dan gas yang dihasilkan masing-masing berada pada bagian sisi reaktor. Tipe cross draft digunaan untuk menghasilkan arang hasil pembakaran dengan kualitas tinggi. 
Pada Gambar 2.5 ditujukan proses gasifikasi dengan tipe Cross draft.

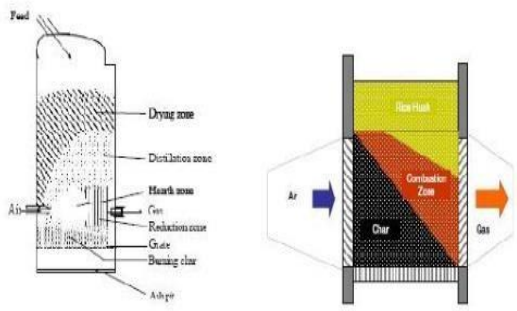

Gambar 2.5 Gasifikasi tipe cross draft

\section{Analisis Uji Performa Kompor Biomassa}

Beberapa parameter penting yang dipertim bangkan dalam menentukan ukuran bahan bakar sesuai dengan kompor dengan memperkirakan output daya yang diharapkan. Dengan demikian ukuran sebuah kompor dapat diperkirakan dengan menggunakan beberapa parameter sebagai berikut:

\subsection{Analisis Uji Performa Kompor Biomassa}

Beberapa parameter penting yang dipertimbangkan dalam menentukan ukuran bahan bakar sesuai dengan kompor dengan memperkirakan output daya yang diharapkan. Dengan demikian ukuran sebuah kompor dapat diperkirakan dengan menggunakan beberapa parameter sebagai berikut:

a. Perhitungan efisiensi termal

Efesiensi termal adalah perbandingan antara nilai kalor yang diterima oleh air dengan nilai kalor yang terkandung dalam bahan bakar. Perhitungan efisiensi termal dilakukan dengan menggunakan persamaan umum yang biasa digunakan metode water boiling test (WBT) sebagai berikut.

$$
\begin{array}{cl}
\text { dengan: } & \eta=\frac{S H+L H}{H F x W F} \times 100 \\
& =\text { Efisiensi termal }(\%) \\
\eta & =\text { Temperatur ahir }(\mathrm{Kcal}) \\
\text { Sh } & \text { L } \\
\text { LH } & \text { panas yang di hasilkan }(\mathrm{Kcal}) \\
\text { HVF } & =\text { Nilai kalor bahan bakar }(\mathrm{Kcal} / \mathrm{kg}) \\
\text { WF } & =\text { Berat bahan bakar }(\mathrm{kg})
\end{array}
$$

b. Power output adalah jumlah energi yang dihasilkan oleh kompor untuk memasak (Belonio, 2005).

$$
\text { Po }=\frac{\text { FCR } \times \text { HVF } \times \text { TE }}{1000}
$$

Po = Daya yang di hasilkan $(\mathrm{Kw})$

FCR = Laju Tingkat konsumsi bahan bakar $(\mathrm{kg} / \mathrm{hr})$

$\mathrm{HVF}=$ Nilai kalor bahan bakar $(\mathrm{Kcal} / \mathrm{kg})$

$\mathrm{TE}=$ Waktu memasak (menit)

c. Heat Energi Input yaitu jumlah energi yang diperlukan dalam hal ini jumlah energi bahan bakar yang diumpankan kedalam kompor dapat ditentukan dengan persamaaan sebagai berikut (Belonio, 2005).

$$
\mathrm{PI}=\mathrm{ES} \times \mathrm{FCR} \times \mathrm{HVF}
$$

$\mathrm{PI}=$ Daya yang di hasilkan $(\mathrm{Kw})$

$\mathrm{ES}=$ Energi spesifik $(\mathrm{Kcal} / \mathrm{Kg})$

\author{
$(\mathrm{kg} / \mathrm{hr})$ \\ FCR = Laju Tingkat konsumsi bahan bakar \\ $\mathrm{HVF}=$ Nilai kalor bahan bakar $(\mathrm{Kcal} / \mathrm{kg}$
}

\section{METODELOGI PENELITIAN}

\section{Waktu dan Tempat}

Pelaksanaan penelitian dilakukan di labolatorium mesin umum produksi pada bulan juli sampai dengan bulan agustus 2018 di Politeknik Gorontalo.

\section{Sistematika Penelitian}

Tahapan penelitian yang akan dilakukan mengikuti diagram alir yang ditunjukan pada Gambar 3.1 sebagai berikut:

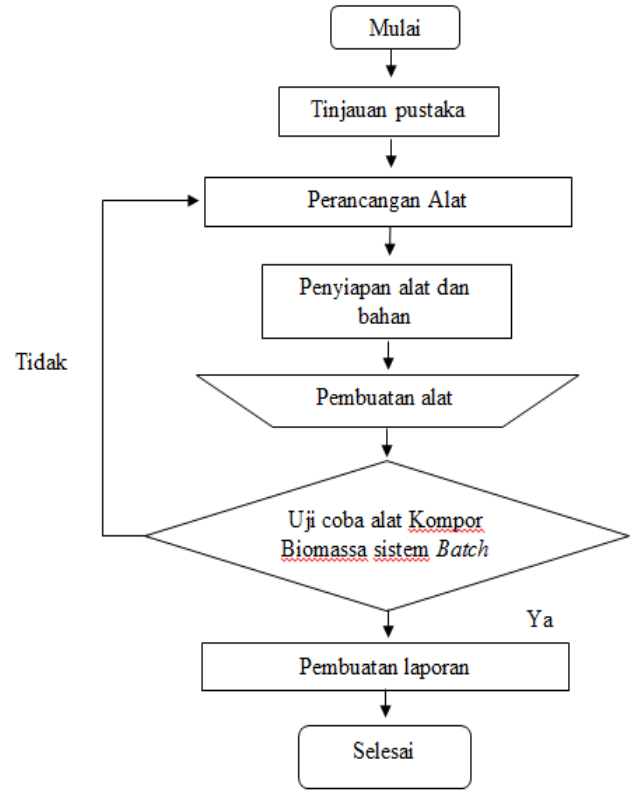

Gambar 3.1. Diagram alir penelitian

\section{Desain Kompor Biomassa Sistem Batch}

Fabrikasi kompor gasifikasi dengan menggunakan sistem batch model yang digunakan pada gasifikasi kompor sebelumnya, maka dilakukan pengembangan model kompor yang akan di dibuat pada penelitian ini. Pengembangan yang dilakukan berupa jumlah laluan udara memelikijari-jari dan penambahan burner/ lubang keluar nyalaapi pada kompor gasifikasi. Rancangan model kompor yang akan dibuat pada penelitian ini ditunjukkan pa da Gambar 3.2 sebagai berikut:

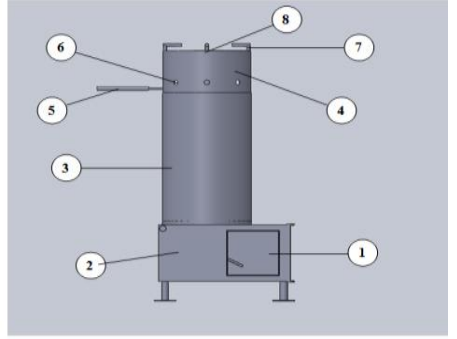

Gambar 3.2. Modifikasi Kompor Biomassa Sistem Batch Pada Tugas Akhir 
Bagian-bagian kompor biomassa system batch :

1. Box Kipas /Blower

2. Box Ash

4. Tabung Reaktor

5. Burner/Kepala Kompor

6. Handle Buner

7. Lubang udara Sekunder

8. Support

9. Lubang Gas Luar

Bagian-bagian Alat Kompor Biomassa Sistem Batch

1. Box Ash

Box ash adalah tempat pemb uangan abu sekam padi serta tempat penyimpanan abu sekam padi hasil pembakaran. Box ash juga menyatu pada bagian blower yang berpungsi mengatur sir kulasi udara yang akan menjadi gas pembakaran.

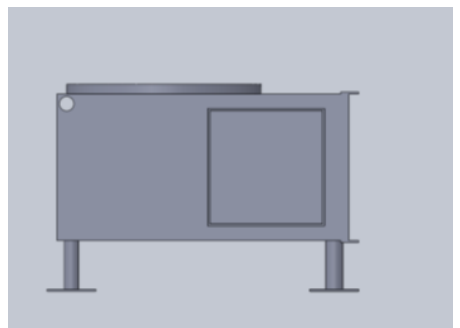

Gambar 3.3 Box ash

2. Saringan Udara

Saringan udara adalah saringan yang membatasi ruang pembakaran dengan ruang box ash agar tidak terjadi saling berkaitan dan tempat keluarnya udara dari kipas/blower.

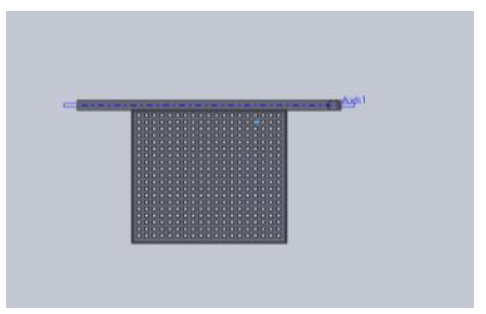

Gambar 3.4. Saringan Udara

3. Tabung Reaktor

Tabung reaktor adalah tempat penampung bahan bakar sekam padi yang kering, sekaligus tempat terjadinya proses pembakaran.

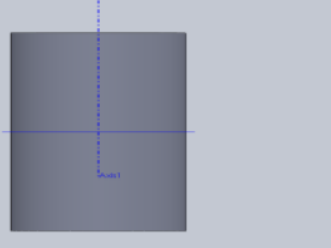

4. Burner Kompor Biomassa

Burner kompor biomassa adalah tempat pembakaran atau kepala kompor yang berpungsi mengeluarkan nyala api yang teratur, kepala kompor memiliki lubang keluar nyala api dan lubang keluar udara serta support/ pendukung ( tempat dudukan ).

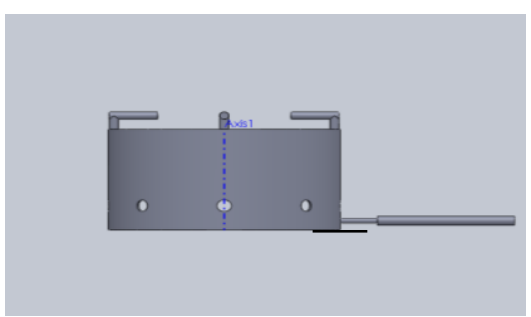

Gambar 3.6. Burner Kompor

5. Blower / Kipas

Bloweer berpungsi sebagai mengatur sirkulasi udara yang akan menjadi udara pembakaran.

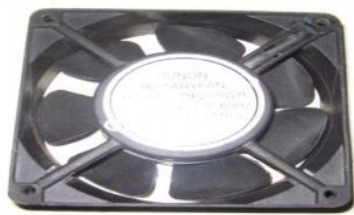

Gambar 3.7. Blower / kipas

\section{PEMBAHASAN DAN HASIL}

Proses Pembuatan Kompor Biomassa Sistem Batch

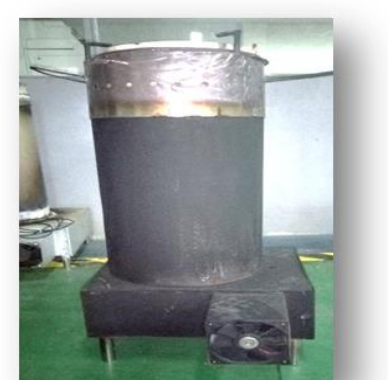

Gambar 4.1 Modifikasi Kompor Biomassa Sistem Batch pada tugas akhir

1. Pembuatan Box Ash

Box ash dibuat menggunakan besi siku berukuran 30x30 mm dengan ketebalan 2 $\mathrm{mm}$ berbahan dasar besi ST 37 dan mengunakan plat essel dengan ketebalan 1,6 $\mathrm{mm}$. Box ash berfungsi sebagai penopang semua rangkaian komponen kompor biomassa sistem beach. Seperti tabung reaktor atau tabung penampung bahan bakar dan burner ataupun disebut kepala kompor. Dan box ash memiliki dimensi panjang $40 \mathrm{~cm}$, lebar box ash memiki $32 \mathrm{~cm}$ dan tinggi $15 \mathrm{~cm}$. 


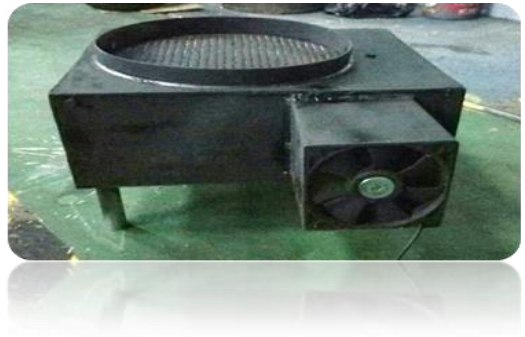

Gambar 4.2 Box ash

2. Pembuatan Saringan Udara

Saringan udara dibuat menggu nakan plat galvanis dengan tebal 1,6 mm. Saringan ini berfungsi sebagai tempat lubang masuknya udara dari kipas/blower untuk membantu terjadinya pembakaran dan saringan ini juga berguna untuk tidak terjadinya salin berkaitan antara ruang pembakaran dan ruang box ash pada proses kompor di nyalakan. Dimensi panjang saringan $38 \mathrm{~cm}$ dan lebar saringan 30 $\mathrm{cm}$, setiap lubang berukuran $5 \mathrm{~mm}$, dengan jarak antara lubang satu dengan yang lainya $10 \mathrm{~mm}$. Tahap pertama pembuatan saringan yaitu melukis permukaan plat menggunakan penitik untuk membuat garis dan mistar baja untuk membantu meluruskan garis yang akan dibuat. Setelah itu potong plat yang sudah memiliki ukuran menggunakan batu gerinda potong. Selanjutnya menggaris permukaan plat lagi untuk membuat lubang saringan dengan jarak setiap garis 10x10 mm, berikutnya membuat lubang di setiap pertemuan garis yang telah dibuat menggunakan mesin frais untuk membuat lubang tersebut dengan mata bor $\varnothing 5 \mathrm{~mm}$.

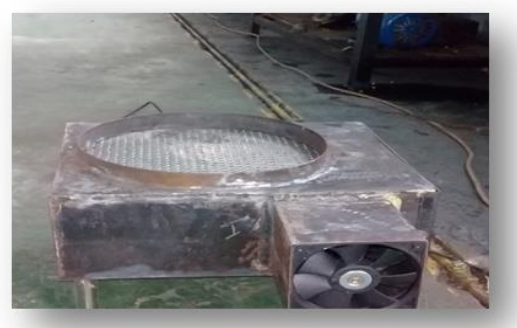

Gambar 4.3 Saringan udara

3. Pembuatan Box Kipas/Blower

Box kipas/blower terbuat dari besi plat essel dengan tebal 1,6 mm yang berfungsi sebagai tempat dudukan kipas untuk membatu proses terjadinya pembakaran pada tabung reaktor. Box kipas/blower memiliki pajang diametr $13 \mathrm{~cm}$, lebar box kipas memiliki $13 \mathrm{~cm}$ dan tinggi box kipas memiliki diameter $13 \mathrm{~cm}$.

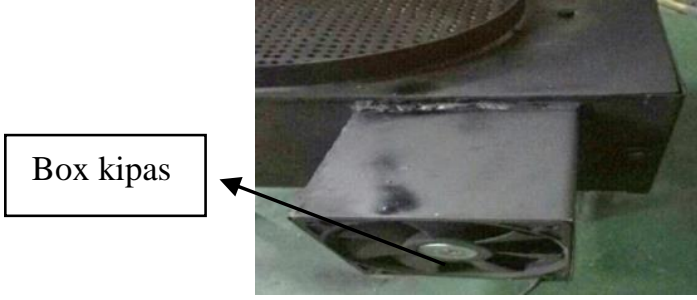

Gambar 4.4 Box kipas

4. Tabung Reaktor

Tabung reaktor terbuat dari plat essel dengan tebal 1,6 $\mathrm{mm}$ bagian luar dan bagian dalam terbuat dari plat galvanis dengan ketebalan 1,6 mm, yang berfungsi sebagai tempat penampung bahan bakar dan sebagai tempat terjadinya pembakaran. tabung bagian luar berukuran tinggi $50 \mathrm{~cm}$, lebar $94 \mathrm{~cm}$ dan diameter lingkaran memiliki $\varnothing 30 \mathrm{~cm}$ dan tabuang bagian dalam berukuran tinggi $50 \mathrm{~cm}$, lebar tabung $78,5 \mathrm{~cm}$ dan berdia meter lingkaran $\varnothing 25 \mathrm{~cm}$.

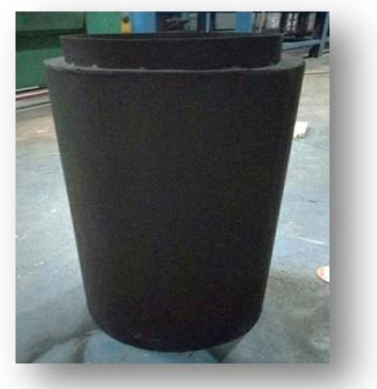

Gambar 4.5 Tabung reaktor

5. Pembuatan Burner (kepala kompor)

Burner atau kepala kompor terbuat dari plat galvanis dengan ketebalan 1,6 $\mathrm{mm}$, yang berpugsi sebagai tempat mengeluarkan nyala api yang teratur,kepala kompor memiliki lubang keluar nyala api dan lubang keluar udara serta support/pendukung (tempat dudukan). Dimensi burner bagian luar memiliki tinggi $20 \mathrm{~cm}$, lebar burner $94 \mathrm{~cm}$ dan berdiameter lingkaran $\varnothing 30 \mathrm{~cm}$ dan bagian dalam burner berukuran tinggi $8 \mathrm{~cm}$, lebar $79 \mathrm{~cm}$ dan berdiameter lingkaran $\varnothing 25 \mathrm{~cm}$.

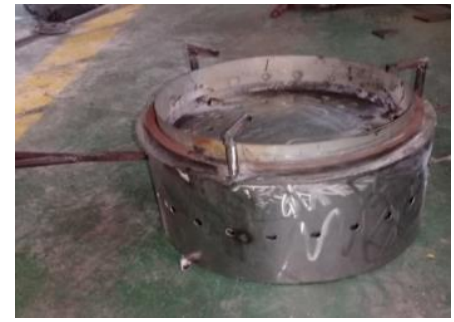

Gambar 4.6 Burner Atau Kepala Kompor 


\section{Proses Perakitan Kompor Biomassa}

Box ash dibuat menggunakan besi siku berukuran 30x30 mm dengan ketebalan $2 \mathrm{~mm}$ berbahan dasar besi ST 37 dan menggunakan plat essel dengan ketebalan 1,6 mm memiliki ukuran panjang $40 \mathrm{~cm}$, lebar box ash $32 \mathrm{~cm}$ dan tinggi $15 \mathrm{~cm}$. Box ash berfungsi sebagai penopang semua rangkaian komponen kompor biomassa sistem bacth. Saringan udara terbuat dari besi plat galvanis dengan tebal 1,6 $\mathrm{mm}$ yang berfungsi sebagai penyaring untuk memisahkan abu dari hasil pembakaran dan tempat masuknya udara dari kipas/blower. Box kipas/blower terbuat dari plat essel yang mempunyai ketebalan 1,6 $\mathrm{mm}$ memiliki ukuran tinggi $13 \mathrm{~cm}$, lebar $13 \mathrm{~cm}$ dan panjang $13 \mathrm{~cm}$. Berfungsi sebagai tempat dudukan kipas/blower. Tabung reaktor dibuat menggunakan besi plat essel dengan ketebalan 1,6 $\mathrm{mm}$ yang berukuran panjang $94 \mathrm{~cm}$, lebar $50 \mathrm{~cm}$, tinggi $50 \mathrm{~cm}$ dan berdiameter lingkaran $\varnothing 30 \mathrm{~cm}$ bagian luar dan bagian dalam tabung reaktor terbuat dari besi plat gakfanis dengan ketebalan 1,6 dan berukuran panjang $78 \mathrm{~cm}$ , lebar $50 \mathrm{~cm}$, tinggi $50 \mathrm{~cm}$ dan berdiameter lingkaran $\varnothing 25 \mathrm{~cm}$. Burner dibuat daribesi plat galfanis dengan 1,6 dan berukuran panjang $94 \mathrm{~cm}$, lebar 20, tinggi 20 dan berdia meter lingkaran $\varnothing 30 \mathrm{~cm}$. Burner atau kepala kompor berpunsi sebagai tempat keluarnya nyala api yang teratur,kepala kompor memiliki lubang keluar nyala api dan lubang keluar udara serta support / pendukung ( tempat dudukan ).

\section{Prosedur Pengujian Kompor}

Pada dasarnya pengujian ini hanya untuk mengetahui apakah alat yang dibuat sesuai dengan yang direncanakan dan mengetahui hasil dari pengujian alat apakah sesuai dengan yang direncanakan dan diharapkan. Adapun langkah-langkah dalam proses pengujian kompor biomassa sistem bacth menggunakan sekam padi adalah:

1. Sediakan sekam padi untuk di jadikan bahan bakar kompor biomassa sisitem bacth.

2. Menyiapkan bejana/panci yang berukuran besar.

3. Siapkan air dan liter untuk mengukur air yang dimasukkan pada panci.

4. Mengisi bahan bakar berupa sekam padi yang sudah berukuran $1 \mathrm{~kg}$ kedalam tabung reaktor.

5. Siapkan selembar kertas untuk dinyalakan sebagai pemicu awal dalam start-up hingga sekam padi terbakar.

6. Siapkan stopwatch untuk menghitung total waktu operasi selama pengujian.

7. Apabila semua peralatan untuk mendukung proses penelitian sudah tersedia maka langkah selanjunya menyalakan kompor.

8. Mengamati proses start-up apakah sudah sempurna.

9. Ketika nyala api sudah terbentuk maka dilakukan pendidihan air dan amati lama waktu proses pendidihan air dengan stopwatch.
10. Pengujian dilakukan sebanyak tiga kali dengan jumlah air yang berbeda-beda.

\section{Data Hasil Pengujian}

Eksperimen pengujian dan evaluasi performa kompor biomassa sistem bacth meliputi data waktu start-up, laju komsumsi bahan bakar (fuel consumption rate), analisis power input, latent heat, sensible heat, efesiensi termal dan power output. Adapun hasil dari data pengujian metode water boling time (WBT) ditujukan pada tabel 4.1 sebagai berikut.

Tabel 4.1 Data Hasil Metode Water Boiling Time (WBT)

\begin{tabular}{|c|c|c|c|c|c|c|c|}
\hline No & $\frac{\text { Berat Bahan }}{\text { Bakar }(\mathrm{kg})}$ & $\begin{array}{l}\text { Star Up/ } \\
\frac{\text { Nyala Api }}{\text { (detik) }}\end{array}$ & $\frac{\text { Jumlah }}{\operatorname{Air}(\mathrm{Kg})}$ & $\begin{array}{l}\frac{\text { Temperatur }}{\text { Suhu Air }} \\
\text { Mendidih }\left(^{\circ}\right)\end{array}$ & $\frac{\frac{\text { Waktu }}{\text { Mendidih }}}{\text { (menit) }}$ & $\frac{\frac{\text { Tempera }}{\text { tur Akhir }}}{\text { (menit) }}$ & $\begin{array}{l}\text { Total Operaas } \\
\text { waktu (menit) }\end{array}$ \\
\hline 1 & 1 & 45 & 1 & 100 & 3,25 & 5,17 & 8,17 \\
\hline 2 & 1 & 48 & 2 & 100 & 5,36 & 8,47 & 12,56 \\
\hline 3 & 1 & 54 & 3 & 100 & 7,23 & 11,09 & 15,28 \\
\hline
\end{tabular}

Tabel 4.1 menunjukkan data hasil pengujian menggunakan metode water boiling time (WBT). Percobaan dilakukan sebanyak tiga kali dengan jumlah bahan bakar yang sama yaitu $1 \mathrm{~kg}$. Berdasarkan data pengujian didapatkan hasil pengujian dengan $1 \mathrm{~kg}$ masa air yang dididihkan menunjukkan total operating time yang paling rendah yaitu 8.17 menit, temperature akhir yang dihasilkan juga lebih kecil dibanding lainnya yaitu sebesar 5.17 menit. Pada pengujian tersebut proses pendidihan $1 \mathrm{~kg}$ air berlangsung cepat yaitu terjadi pada menit ke 3.25. Hal ini dapat terjadi karena kompor terisi bahan bakar sekam padi yang mempunyai sifat pembakaran berkelanjutan sehingga nyala api lebih besar. Sedangkan percobaan ketiga dengan $3 \mathrm{~kg}$ masa air yang dididihkan menunjukkan total operating time yang paling tinggi yaitu 15.28 menit, temperature akhir yang dihasilkan juga lebih besar yaitu sebesar 11.09 menit. Pada pengujian tersebut proses pendidihan $3 \mathrm{~kg}$ air berlangsung agak lama yaitu terjadi pada menit ke 7,25 . Hal ini dapat terjadi karena kompor masih terisi abu sekam padi yang mengendap akibatnya tekanan udarapun berkurang naik keatas sehingga temperature akhir lebih lama padam. Proses pengujian kompor biomassa sistem bacth menggunakan bahan bakar sekam padi dapat ditunjukkan pada Gambar 4.7 sebagai berikut.

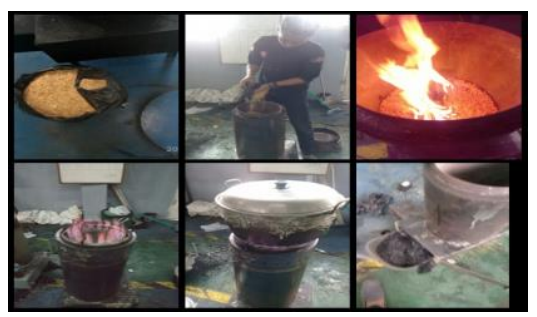

Gambar 4.7 Proses Uji Coba Kompor Biomassa Sistem Bacth 


\section{Analisis Performa Biomassa Sistem Bacth}

Mengetahui performa atau kinerja kompor biomassa tipe downdraft system continue ialah dengan cara menghitung parameter power output, input, laju bakar, effesiensi termal guna mengetahui perbandingan antar kompor sebelumnya. salah satunya yang pernah dibuat oleh (Djafar, dkk 2017).

\section{a. Hubungan Power Output terhadap Jumlah air yang didihkan}

Power output adalah jumlah panas yang dikeluarkan untuk mendidihkan air, Power output di uji dari jumlah air yang dididihkan sebanyak 3 kali pengujian dengan jumlah masa air yang berbeda $(1,2,3) \mathrm{kg}$, tetapi menggunakan berat bahan bakar yang sama yaitu $1 \mathrm{~kg}$. pengujian 1 diperoleh power output terendah $0.83 \mathrm{kw}$ untuk jumlah masa air $1 \mathrm{~kg}$, sedangkan power output tertinggi $1.80 \mathrm{kw}$ dilakukan pada pengujian 3 untuk jumlah masa air $3 \mathrm{~kg}$. dapat dilihat pada grafik gambar 4.8 sebagai berikut.

Gambar 4.8 Hubungan Power Output Terhadap Jumlah

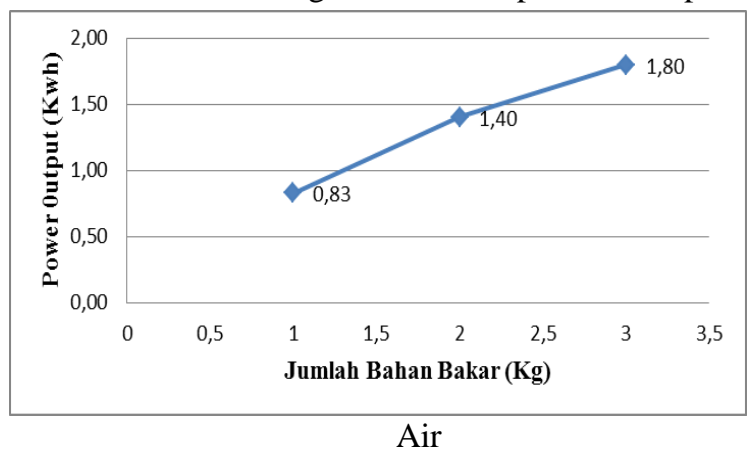

Dari gambar diagram grafik diatas menunjukkan bahwa semakin banyak jumlah air yang didihkan semakin banyak pula power output yang diperlukan. Hal ini terjadi dikarenakan penumpukan abu bahan bakar yang mengakibatkan terhambatnya tekanan udara yang dikeluarkan, sehingga sangat berpengaruh pada input udara yang masuk maupun bahan bakar yang ditambahkan.

\section{b. Hubungan Power Input terhadap Jumlah air yang didihkan}

Power input adalah jumlah bahan bakar yang diperlukan untuk mendidihkan air, power input di uji dari jumlah air yang dididihkan sebanyak 3 kali pengujian dengan jumlah masa air yang berbeda $(1,2,3)$ $\mathrm{kg}$ menggunakan penambahan bahan bakar secara terusmenerus yang mempunyai berat bahan bakar sama yaitu $1 \mathrm{~kg}$. Pengujian 1 diperoleh power input terendah $1,9 \mathrm{kw}$ untuk jumlah masa air $1 \mathrm{~kg}$, sedangkan power input tertinggi 3,4 kw dilakukan pada pengujian 3 untuk jumlah masa air $3 \mathrm{~kg}$. dapat dilihat pada diagram batang gambar 4.9 sebagai berikut.

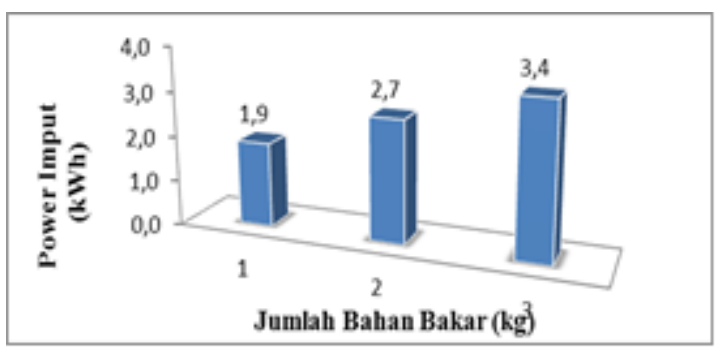

Gambar 4.9 Diagram Batang power input

Dari gambar diagram batang diatas menunjukkan bahwa semakin banyak jumlah air yang didihkan semakin banyak pula power input yang diperlukan. Hal ini terjadi dikarenakan laju konsumsi bahan bakar yang dipasok pada tingginya tabung silinder, sehingga sangat berpengaruh pada power input maupun power output.

\section{Efesiensi Termal Kompor Biomassa Sistem Batch}

Efesiensi termal adalah perbandingan antara nilai kalor yang diterima oleh air dengan nilai kalor yang terkandung dalam bahan bakar. Dari hasil data perhitungan berupa power input,output, dan laju konsumsi bahan bakar dan efesiensi maka didapatkan hasil di tunjukkan pada Tabel 4.2 sebagai berikut.

\begin{tabular}{|l|l|l|l|l|}
\hline $\begin{array}{l}\text { SH.(Kc } \\
\text { al) }\end{array}$ & $\begin{array}{l}\text { LH.(Kc } \\
\text { al) }\end{array}$ & $\begin{array}{l}\text { HVF.(Kcal/ } \\
\text { Kg) }\end{array}$ & $\begin{array}{l}\text { WF.(K } \\
\text { g) }\end{array}$ & $\begin{array}{l}\text { EFF. } \\
(\%)\end{array}$ \\
\hline 225 & 1620 & 2582.3 & 3 & $\begin{array}{l}23.81 \\
6\end{array}$ \\
\hline & & & 23.81 \\
150 & 1080 & 2582.3 & 2 & 6 \\
\hline & & & & $\begin{array}{l}23.81 \\
6\end{array}$ \\
\hline
\end{tabular}

Tabel 4.2 menunjukkan tiga kali percobaan di dapatkan efesiensi cenderung sama. Hal ini dapat terjadi karena jumlah bahan bakar di suplai pada kondisi konstan. Disamping itu bahwa diamati energi kalor yang tersedia dalam bahan bakar semakin besar seiring bertambahnya bahan bakar secara teru-menerus. Dengan demikian dapat disimpulkan bahwa efisiensi yang di hasilkan sebesar $23,8 \%$ dan lebih baik dari desain kompor sebelumnya ((Djafar, dkk 2017)).

\section{PENUTUP}

\section{Kesimpulan}

Dari hasil pengujian dan analisis data pengujian kompor biomassa sisitem bacth dengan 3 variasi ukuran masa air, dapat diambil kesimpulan sebagai berikut:

1 Ukuran kompor biomassa berdiameter luar $30 \mathrm{~cm}$, ruang bakar memiliki $\varnothing 25 \mathrm{~cm}$, tinggi total $95 \mathrm{~cm}$ serta Gap antara dinding luar dan ruang bakar sebesar $2.5 \mathrm{~cm}$ berisikan glashul.

2 Hasil analisis menunjukkan bahwa ukuran bahan bakar untuk masa air hanya dapat berpengaruh pada endapan abu bahan bakan menjadikan siklus pembakaran lebih lama. 
3 Komsumsi bahan bahkar berturut-turut didapat sebesar $1,1 \mathrm{~kg} / \mathrm{h} ; 1,9 \mathrm{~kg} / \mathrm{h}$ dan $2,5 \mathrm{~kg} / \mathrm{h}$.

4 Total operating time dari kompor masing-masing sebesar 8,17 menit,13,36 menit dan 15,28 menit.

5 Power input berdasarkan hasil analisis masingmasing pada percobaan petama sebesar $3,6 \mathrm{kw}$, percobaan kedua $6,1 \mathrm{kw}$ dan percobaan ketiga sebesar 7,8 kw .

6 Berdasarkan hasil analisis didapatkan power output terendah sebesar 0,$8 ; 1,4$ dan $1,8 \mathrm{kw}$.

7 Efesiensi kompor biomassa sisitem bacth pada penelitian adalah sebesar 23,8\%. Disimpulkan bahwa efesiensi kompor biomassa ini lebih tinggi sedikit dibandingkan efesiensi kompor biomassa sebelumnya.

\section{Saran}

Dari pembuatan kompor biomassa sistem bacth sudah menghasilkan pembakaran yang efektif yaitu menimbulkan nyala api ke biru-biruan. Untuk proses modifikasi yang akan datang kompor ini masih menggunakan tipe batch atau satu kali tuang bahan bakar. Untuk pengembangan kedepannya kompor biomassa sistem batch ini dapat dimodifikasi dengan menambahkan corong input agar dapat menghasilan proses pembakaran yang berkelanjutan atau terusmenerus (continue)

\section{DAFTAR PUSTAKA}

Alexis T, Belonio (2005). Rice Husk Gas Stove Handbook. Departement of Agricultural Engineering and Environmental Management College Of Agriculture, Philippine.

Anonimous, 2010. Jenis-jenis Biomassa. pendidikan. Diakses 26 juni 2014. pukul 09.42 WITA.

Babu, B.V. and Chaurasia, A.S. (2003). Modeling for Pyrolysis of Solid Particle: Kinetics and Heat Transfer Effects.

Badan Pusat Statistik (BPS), 2012. Produksi padi, jagung, kedelai angka ramalan I tahun 2012. Jakarta (ID): BPS

Bhattacharya, S.C, Augustous Leon,A., \& Khaing, A.M. (2002) Water Boiling Time. Thailand: Asian Institute of Technology.
Basu, Prabir. 2013. Biomass Gasification, Pyrolisis, and Torrefaction (Partical design and Theory). Elsevier Inc: London.

Djafar, dkk 2017. Pengaruh Ukuran Bahan Bakar Tongkol Jagung Terhadap Performa Kompor Gasifikasi Biomassa Tipe Forced Draft.

H. S. Mukunda*, S. Dasappa, P. J. Paul, N. K. S. Rajan, Mahesh Yagnaraman, D. Ravi Kumar and, (2010). Gasifier stoves - science, technology and field outreach. General artickel.

Lembaga Penelitian dan Pengabdian kepada Masyarakat Institut Pertanian Bogor (LPPM IPB). 2008. Mengenal lebih dekat tungku sekam IPB. Diakses pada tanggal 11 Februari 2016.

Madhiyanon, T. , al al. 2010. Combustion Characteristics of Rice-Husk In A Short-Combustion-Chamber Fluidized-Bed Combustor. Bangkok, Thiland: Mahanakorn University of technology.

Prabowo, Nandana Dwi, (2010), "Pengaruh Variasi Air Fuel Ratio (AFR) dan Ukuran Biomassa Terhadap Gasifikasi Biomassa Ampas Tebu pada reaktor Downdraf Sistem Batch", ITS

UB-03 Nurhuda Nurhuda, M. 2008. Мепији Kemandirian Energi Bagi Rakyat Miskin dengan Kompor Bimassa UB. Artikel. Universitas Brawijaya. Malang. 
